\title{
Self-development and Self-protection of China Pu'er Whipping Top Project from Perspective of Sports Intangible Cultural Heritage
}

\author{
Dongying Li \\ School of Physical Education \\ Yunnan Minzu University \\ Kunming, China
}

\begin{abstract}
In the process of protection and development of Asian minority traditional sport, the traditional sports intangible cultural heritage faces the impact of modern sport, the contradiction between technological progress and the protection of tradition, the insufficient inheritors and others difficulties. This paper takes the exploration of origin of the ancient whipping top event as the background to conduct the field survey on the development and protection of whipping top events in Jinggu Country, Yunnan, China, while result found that in Jinggu, whipping top event has been perfect protected with governmental legislation and mass participation. In order to better protect and develop the whipping top event, how to promote it enter the younger generation of the campus community and integrate it enter the minority festival will be a new breakthrough.
\end{abstract}

Keywords-sports intangible cultural heritage; traditional sports culture; whipping top

\section{INTRODUCTION}

In the process of protection and development of Asian minority traditional sport, the traditional sports intangible cultural heritage faces the impact of modern sport, the contradiction between technological progress and the protection of tradition, the insufficient inheritors and others difficulties. This paper takes the exploration of origin of the ancient whipping top event as the background to conduct the field survey on the development and protection of whipping top events in Jinggu Country, Yunnan, China, while result found that in Jinggu, whipping top event has been perfect protected with governmental legislation and mass participation. In order to better protect and develop the whipping top event, how to promote it enter the younger generation of the campus community and integrate it enter the minority festival will be a new breakthrough of Sports intangible cultural heritage, as an important part of the human cultural heritage, plays an important role in the evolution of human civilization. As an intangible cultural heritage, the minority traditional sport is different from other types of sport, and the origin and development of minority traditional sport are accompanied by the festive ceremony and folk customs of this nation with a strong region, entertainment and mass participation, which is a part of the national spirit and cultural heritage and is the guarantee to ensure our national diversity. In the economic context of rapid development, many ethnic traditional sport accumulated and developed from the farming community have been affected by the Western modern industrial development, and many ethnic traditional sports events are gradually fading out of mainstream sports culture. And the major manifestations of many minority traditional sports are as follows: worship, festivals, etc., have been forgotten in the fast-paced urban life, and the development of minority traditional sport loses its core content, so as to increase the difficulty of our protection to minority traditional sport. In protection of minority traditional sport also is the inevitable requirement in the progress of our human civilization and is the important part to achieve coordinated development between national material civilization and spiritual civilization.

\section{RESEARCH METHODS}

\section{A. Method of Literature}

It has reviewed the document relating to intangible cultural heritage, the intangible cultural heritage of sports and recreation and retrieves the Chinese intangible cultural heritage network and the relevant guidance documents, news reports and related research achievements in the Yunnan intangible cultural heritage sites.

\section{B. Field Interviews}

Through interviewing the officer in charge and local villagers in the protection department of intangible cultural heritage, the paper understands the development condition and current problems of local intangible cultural heritage; the author come to Pu'er, Jinggu and other places to conduct field interview and research.

\section{RESEARCH RESULT}

\section{A. History of Ancient Pu'er Whipping Top Event in Yunnan}

As the development area of the second batch of sports and recreation intangible cultural heritage projectwhipping top in Yunnan Province, Jinggu has already had the records about whipping top event in the Emperor Yongzheng Period of Qing Dynasty (according to records of Jinggu County). 
According to records, a tribal leader named Li Si invented this event with rope to whip the top under the inspiration of Li Shigui who followed him, and after the creation of the whipping top, this project gradually had been spread from the village to the surrounding villages. The villages nearby gradually formed a folk whipping top competition among villages. From the beginning of New Year each year to a small 16th Day gradually formed a local "Whipping Top Festival". Whipping top game had been spread to Longtan Village to the whole county, and even Dai Nationality, Lahu Nationality and other brother nations outside the county. In the Republic of China 23rd Year (1934), the whipping top event had entered an era of rapid development, while Gong Chenggui, Liao Fa and others who were Yi Zhi people were recruited as members of Yunnan Army, garrisoning Kunming, and theyjust produced the top on the spot and organized the local villagers to whip the top in the holiday s. Meanwhile, the soldiers in Xiangyun, Shuangbai, Dali, Xinping and other counties learned to play whipping the top. Such whipping top event had been quickly popularized in Yunnan Province. In the public eye, the top generally is to compete the duration of the rotation in place to determine the winners and losers, noting in the dictionary as "children's toy with the sharp needle on the lower part and the string around, which is thrown quickly to rotate on the ground". Interpretation in the encyclopaedia is that "top is made of wood, as small as an air bell, while it the solid inside without handle, whipping it with a rope on the ground, quickly whipping the rope. Whip it once, the top will silently rotate. If it slows down, people will whip it again, it will rotate again. If it is rotating too quickly, it looks like standing out on the ground with light on top, but the shadow does not move either". However, the top in the Jinggu County is a kind of competitive sport with transition between attack and defense, and the main features are the "spinning" and "accuracy".

\section{B. Development Condition of Modern Whipping Top Event}

1) Development condition of whipping top event in $P u$ 'er: Now Jingu County has eight counties and four towns, a total of 132 village committees, while minority population accounts for $46.3 \%$, which mainly are Dai Nationality and $\mathrm{Yi}$ Nationality. At the same time, Han Nationality, $\mathrm{Nu}$ Nationality, Jino Nationality and other minorities still inhabit in the county. In the small county with only 29 million people, every day the whipping top fans will compete with each other in the venue. Sometimes even the conflict appears in the village, which will be solved by using the whipping top competition. Every New Year, each village will hold a regular whipping top game.

2) Development condition of whipping top event in other places of Yuannan: In Yunnan Province, beside the whipping top event has been carried out widely in Pu'er City, its development is very good also in Xishuangbanna, Xinping in Yuxi, Chuxiong City, Huanan County, while Shuangbai County in Chuxiong also is the protected territory of the whipping top event that is the traditional sports and entertainment intangible cultural heritage item in
Yunnan Province. These regions all have perfect venue for whipping top competition, while the venues of whipping top event in the city center also are equipped with lights and at night, people can continue whipping the top to exercise the body.

\section{Path of Protecting and Promoting Whipping Top Event in Jing Cultural Heritage}

Government lists the whipping top project into Development Project of "12th Five-Year Plan" The government takes declaring "whipping top" sports athletic event to the national intangible cultural heritage protection list as an opportunity to increase the effort of exploring, collecting and declaring the whipping top, this intangible cultural heritage item.

1) Setting up the regulation of relevant protection: On January 13, 2013, passed in the 16th NPC at its 1st Session of Jinggu Dai and Yi Nationality Autonomous County, on March 28, 2013, the second meeting of the 12th Standing Committee of the people's Congress in Yunnan Province approved the Ethnic and Folk Traditional Culture Protection Regulations of Yunnan Jinggu. Dai and Yi Autonomous County. The first article of the regulation emphasized that in order to protect, inherit and carry forward the fine ethnic and folk traditional culture, develop the ethnic culture career and promote the coordinated economic and social development, according to the Regional National Autonomy Law of the People's Republic of China, Intangible Cultural Heritage Law of the People's Republic of China and other relevant laws and regulations, combined with reality of Jinggu Dai and Yi Autonomous County (hereinafter referred as autonomous county), it formulates the relevant regulations of protection. While the third aspect of the third article pointed out the etiquette, festivals, sport, recreation and religious culture belongs to the protection objects of this regulation. The regulations provide the legal guarantee for the local government to protect the development of sports and recreational intangible cultural heritage - the whipping top event.

2) Walking on the promotion path of mass line: The number of people who often participate in whipping the top to exercise the body in Jinggu county and township is maintained at more than 1,000 people, while there are more than 1600 venues that can provide for mass exercise, and there are more than 40 whipping top venues around the county. More than 6 million people in the whole county have participated in the whipping top event, so the most direct way is to walk the mass line, and then Jinggu can better develop and promote the whipping top event. In the survey, it also found that, in fact, not only Jinggu carries out the whipping top event better in Pu'er, but also the development of the whipping top event, the venue construction of the whipping top event, and the number of people who participate in the whipping top event in other eight counties and one district are as well as Jinggu County. 
3) Way of competition and communication: Behind a sports event that has been successful carried out in global area, there will the sound rules of the game the mature business operation of game as a solid backup force. Through the exchange of game, more people can understand the whipping top event, while it can train the athletes of the whipping top to communicate in other places, which both help the top athletes in other places to raise the level of technique, but also can indirectly make the local people contact the whipping top event.

4) Cultivating youth sports talent: For Jinggu County does not have the professional sports training team, in September 2007, Pu'er City established the whipping top team in Pu'er Middle School for professional training. It trains six men and six women, which are composed of the young people from Yi Nationality, Lahu Nationality, Hani Nationality, Bulang Nationality and Hui Nationality, while the youngest is 14 years-old and the oldest is 16 years-old.

5) Manufacture of top equipment: Top equipment itself can be used as an instrument of culture for inheritance and dissemination. The top in the past is made of wood, which is manufactured by knife and axe during the interval when people go to the mountain to cut firewood, and their size varies according to people. But in tradition, there is the scope, while the general height is $12-15 \mathrm{~cm}$ and diameter is $9-12 \mathrm{~cm}$. After $80 \mathrm{~s}$, people use the lathe to process and make the top for competition, and it can make all kinds of tops, so the traditionally folk handmade top has gradually disappeared, and the nails of the top also are transited from the soil nails in the past to the steel nails, gradually developing towards more wear-resisting nails and aluminum nails.

In the formal whipping top game, there are already the standardized provisions of the top and whipcord. In competition, it regulates that the top cannot be colored, in addition that the cone tip can installed the metal nail with diameter that cannot exceed $0.4 \mathrm{~cm}$, it should not be filled or decorated by metal or other materials; the top has $9-10 \mathrm{~cm}$ of diameter and 10-12 cm of height, while the height of the top cylinder is $5-6 \mathrm{~cm}$ and the weight is $800-900$ grams. The whipcord should not use metal material to manufacture, and the thickness will not be limited, while the length of the men's whipcord is 6 meters, the length of the women's whipcord is 5 meters, and the length of whip pole should not exceed $60 \mathrm{~cm}$. With the peer-standard of game, the craftwork to make the top can be more simple and easier. Whipcord and whip pole continue to advance and develop. Previous whipcord is twisted by the cotton thread or a sewing machine line, but the whipcord made by this kind of material is easily broken. Subsequently, the whipcord made by lashing wire of cement bag has been gradually replaced by twine, and the current material is fetal hair that is a kind of material to make a rubber tire and is very strong and very difficult to break. The whip pole in the past can use the branch, while the playing method in some areas does not need the whip pole.

\section{Problems and Difficulties that Jinggu Faced in Protection and Development of Whipping Top Project}

1) Impact of western modern sport on whipping top event: A scene took place in the process that Professor Liu Jian investigated Mi Le Ke Yi Village: in the village, the villagers of older generation all were carrying out the exercise way of the traditional sport, while the pupils at one side were holding racket that was made by cardboard and used the bricks as a net on the concrete floor to play the table tennis, although the instrument was simple, pupils were still playing exceedingly happy. In the process of our research, we also found the similar problems, on the whipping top courses that were everywhere in Jinggu County, most were the old people at 50 years-old or older. We randomly interviewed some elderly people and found the reason why older people were keen to whipping top event is that they liked this sports event due to influence by what one constantly sees and hears in childhood, while whipping the top could also exercise the body; however, the middle-aged people were in the phase that they can play or may not play, while they can play if some people organized, coupled with many sports activities right now, they had more choices, so the middle-aged people would less be obsessed with the whipping top event. The young men can be exposed to more modern Western sports event when they go to school and go to work outside, and coupled with busy learning and work, they have very little time to run the whipping top game, but only in the holidays and festive time, they are able to participate in the whipping top event inside the village or when some people specifically organize the whipping top competition.

2) Insufficiently extensive degree of development by school sport: The research found that the teaching contents of current physical education classes in the most of primary and secondary schools mainly are running, jumping rope, basketball, volleyball and other Western sports activities, and only a handful of schools can extensively take the whipping top event as the physical education.

3) Insufficient propaganda strength of intangible cultural heritage event:Incomplete Mass Understands to Intangible Cultural Heritage We randomly interviewed the people in Jinggu County, and almost everyone knows the whipping top event. But the number of people knowing that the whipping top event has been included in the intangible cultural heritage of Yunnan province is almost zero.

4) Insufficient social power: The research found that the plate of traditional sports and recreational intangible cultural heritage can even not be found on the website of current Yunnan intangible cultural heritage protection. Secondly, they are not closely enough linked to the colleges and universities. We can give full play to the function of colleges and universities and organize the scientific research institutions, experts and scholars to promote theoretical research and academic exchange of intangible cultural heritage, while they also can organize the inheritors to the 
colleges and university to study and teach skills, and the inheritors can also learn some systematic knowledge to promote their own development.

5) Contradiction between technical progress and protecting tradition: In the process of the whipping top development, we found that the equipment of the whipping top all make the unification of standards to the top and whip pole in order to facilitate promotion. However, the research group found through visiting that, among the people, there still are a lot of different shapes of tops, many of which are the top handmade by the people themselves. The shapes of the top also have its geographical characteristics, such as the Termitomyces top is in Lincang, and the shape of top is quite similar to the shape of Termitomyces that is endemic plant in Yunnan. So in the process of protection, the promotion of the whipping top event requires the standardization, while the protection of intangible cultural heritage needs the diversity, thus forming a pair of contradiction. The standardized promotion mode and the advances in technology make the intangible cultural heritage gradually lose inner implication and mystique.

\section{CONCLUSION}

\section{A. Research Conclusion}

- The whipping top event in Jinggu County had the records as far back as the Qing Dynasty, but the area of origin of this sport is still unable to be traced.

- The development of the whipping top event in Jinggu County, Pu'er City, Yunnan Province has been very developed and protected well. The government provides the official support for the whipping top event from development plans and law. Also it uses a good mass base to continuously promote the whipping top event from personnel training, actively participating in and hosting the whipping top competitions and the evolution and production of top equipment, in order to protect the charm and cultural connotations of this traditional sport.

- Under the influence of the modern movement, the whipping top event also faces the declining participation degree of young people, insufficient social attention and other issues. Meanwhile, the school sport also pays less attention to the whipping top event, leading to inadequate development and promotion strength of the whipping top event in the school.

- A pair of contradiction between technological progress of the whipping top event and the protecting tradition also is the focus needing to be paid attention and solved in the future.

\section{B. Research Suggestions}

- Jinggu County should seize the opportunity to promote the whipping top event to become a item of national intangible cultural heritage.
- It should introduce the whipping top event in the curriculum of local school physical education, increasing young people's understanding to this project.

- It should set the project display in festivals and use the linkage mechanism of tourist economics to better inherit and promote the whipping top event.

\section{REFERENCES}

[1] Sun HaoLiang, Wang Jing, Discussion on Intangible Cultural Heritage Protection of National Traditional Sport [J], Academic Journal of Guizhou Normal University, Edition of Social Science, 2009 (5): 58-62

[2] Liu Jian, Research on Protection and Inheritance of Minority Traditional Sports Intangible Cultural Heritage [D], Beijing Sports University, 2012

[3] Anna Catalani, Displaying Traditional Yoruba Religious Objects in Museums: The Western Re-Making of a Cultural Heritage [J], Library Trands, 2007(56):66-79

[4] Howard and David Pinder, Cultural Heritage and Sustainability in the Coastal Zone: Experiences in South West England [J], Journal of Cultural Heritage Volume, 2003(4):57-68 